\title{
Effects of Grain Boundary Constraint on the Constitutive Response of Tantalum Bicrystals
}

\author{
A. Ziegler, G.H. Campbell, M. Kumar, J.S. Stölken
}

This article was submitted to

Materials Research Society Spring Meeting

San Francisco, CA, April 22-24, 2003

\section{April 8, 2003}

U.S. Department of Energy

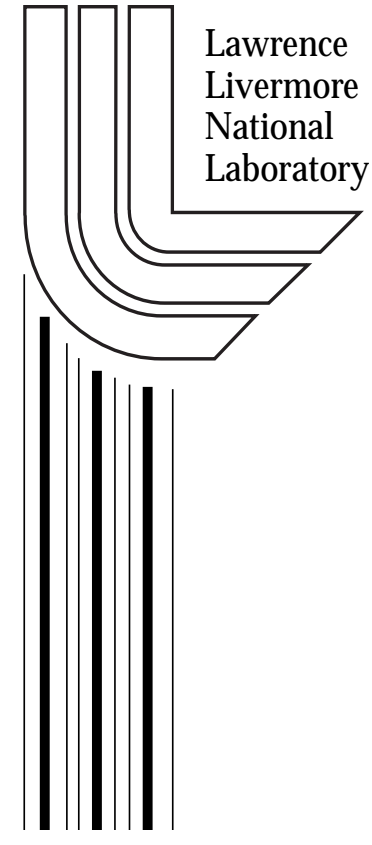




\section{DISCLAIMER}

This document was prepared as an account of work sponsored by an agency of the United States Government. Neither the United States Government nor the University of California nor any of their employees, makes any warranty, express or implied, or assumes any legal liability or responsibility for the accuracy, completeness, or usefulness of any information, apparatus, product, or process disclosed, or represents that its use would not infringe privately owned rights. Reference herein to any specific commercial product, process, or service by trade name, trademark, manufacturer, or otherwise, does not necessarily constitute or imply its endorsement, recommendation, or favoring by the United States Government or the University of California. The views and opinions of authors expressed herein do not necessarily state or reflect those of the United States Government or the University of California, and shall not be used for advertising or product endorsement purposes.

This is a preprint of a paper intended for publication in a journal or proceedings. Since changes may be made before publication, this preprint is made available with the understanding that it will not be cited or reproduced without the permission of the author.

This report has been reproduced directly from the best available copy.

Available electronically at http://www.doc.gov/bridge

Available for a processing fee to U.S. Department of Energy

And its contractors in paper from

U.S. Department of Energy

Office of Scientific and Technical Information

P.O. Box 62

Oak Ridge, TN 37831-0062

Telephone: (865) 576-8401

Facsimile: (865) 576-5728

E-mail: reports@adonis.osti.gov

Available for the sale to the public from

U.S. Department of Commerce

National Technical Information Service

5285 Port Royal Road

Springfield, VA 22161

Telephone: (800) 553-6847

Facsimile: (703) 605-6900

E-mail: orders@ntis.fedworld.gov

Online ordering: http://www.ntis.gov/ordering.htm

OR

Lawrence Livermore National Laboratory

Technical Information Department's Digital Library

http://www.llnl.gov/tid/Library.html 


\title{
Effects of Grain Boundary Constraint on the Constitutive Response of Tantalum Bicrystals
}

\author{
A. Ziegler ${ }^{1}$, G. H. Campbell ${ }^{1}$, M. Kumar ${ }^{1}$ and J. S. Stölken ${ }^{2}$ \\ ${ }^{1}$ Material Science and Technology Division, \\ ${ }^{2}$ New Technologies Engineering Division, \\ Lawrence Livermore National Laboratory, University of California, Livermore, CA 94551, USA
}

\begin{abstract}
The role of grain boundary constraint in strain localization, slip system activation, slip transmission, and the concomitant constitutive response was examined performing a series of uniaxial compression tests on tantalum bicrystals. Tantalum single crystals were diffusion bonded to form a (011) twist boundary and compressed along the [011] direction. The resulting threedimensional deformation was analyzed via volume reconstruction. With this, both, the effective states of stress and strain over the cross-sectional area could be measured as a function of distance from the twist boundary, revealing a highly constrained grain boundary. Post-test metallurgical characterization was performed using Electron Back-Scattered-Diffraction (EBSD). The results, a spatial distribution of slip patterning and mapping of crystal rotation around the twist-boundary was analyzed and compared to the known behavior of the individual single crystals. A rather large area near the grain boundary revealed no crystal rotation. Instead, patterns of alternating crystal rotation similar to single crystal experiments were found to be some distance away $(\sim 400 \mu \mathrm{m})$ from the immediate grain boundary region, indicating the large length scale of the rotation free region.
\end{abstract}

\section{INTRODUCTION}

Crystal plasticity models rely on essential information obtained from experiments analyzing the materials response to mechanical deformation. Such information is critical when considering the rather complex nature of polycrystal deformation that, besides developing heterogeneous patterns of local slip and grain boundary-dislocation interactions shows also pronounced length scale effects, i.e., particle hardening, nano-indentation hardening, Hall-Petch effect. This length scale effect is crucial when attempting to understand and realistically model plastic deformation mechanisms. Finite element calculations [1,2] have demonstrated that heterogeneous intergranular deformation patterns are a result of the combination of compatibility and equilibrium criteria of neighboring grains. However, the grain boundary itself with its characteristic and dynamic phenomena such as slip transmission and blocking, dislocation nucleation and dislocation source activation [3] has been ignored as such in crystal plasticity models. Efforts to incorporate grain boundaries into such crystal plasticity models, have so far been regarding the grain boundary as merely a region of static displacement continuity. This is too simplistic an approach for theoretical models attempting to describe more complex phenomena, i.e., hardening of a polycrystalline material.

The objective of this investigation is to conduct model experiments involving the grain boundary of a uni-axially deformed bicrystal. The prospect is to understand the relevant plastic deformation behavior and to obtain key experimental observations that allow extracting critical parameter in order to inform crystal plasticity models. Useful information about the pertinent 
phenomena that are involved during deformation of a bicrystal can be best obtained if a few desired attributes of the model experiment are fulfilled, i.e., simple sample geometry, well characterized initial specimen configuration with a well defined loading condition, i.e., far-field stress state, limited specimen boundary-grain boundary interactions, and sufficient diagnostic and analysis tools.

\section{EXPERIMENTAL PROCEDURES}

Tantalum single crystals for this investigation were grown from high purity material at the Institute for Solid State Physics in Chernogolovka, Russia into cylinders oriented along [013]. Further purification was achieved via zone refining in high vacuum. Slices of single crystal were obtained and oriented using Laue back-reflection x-ray diffraction in order to cut cylinder shaped single crystals with [011] longitudinal axis. After polishing and lapping all cylinder ends flat and parallel, the bicrystal was composed by parallel alignment of the [011] axes of both single crystals with a grain boundary perpendicular to the compression axis, see Fig. 1. The grain boundary was chosen to be a $90^{\circ}$ twist boundary, thus resulting in maximal misorientation for a BCC lattice. This configuration provided for symmetrical loading and therefore an identical far-field stress state and response to compression deformation in both single crystals, even at large strains. Additionally, it allowed for a multi-axial stress state at the grain boundary to be solely a function of the grain boundary geometry and the applied uni-axial loading.

The bicrystal was diffusion bonded at $1500^{\circ} \mathrm{C}$ under $1 \mathrm{MPa}$ for 8 hours in ultra high vacuum (UHV) and further annealed at $2400^{\circ} \mathrm{C}$ in UHV for 10 hours in order to remove impurities [4], resulting in final cylinder specimen dimensions of $5.95 \mathrm{~mm}$ in diameter and $18.6 \mathrm{~mm}$ in height.

The uni-axial compression loading was performed using an Instron 1127 short frame test nmachine, deforming the specimen in $10 \%$ increments to a $30 \%$ total engineering strain at a strain rate of $10^{-4} \mathrm{~s}^{-1}$. The overall deformation behavior was then analyzed via topographic volume reconstruction that allowed determination of the effective states of stress and strain over the cross-sectional area, measured as a function of distance from the grain boundary. The grain boundary profile was analyzed and finally post-test sectioning of the sample allowed EBSD scans to explore variations in local lattice rotations. For EBSD, individual lattice orientation measurements were performed at discrete points on the sample, which were subsequently used to construct lattice rotation maps of the investigated area [5].

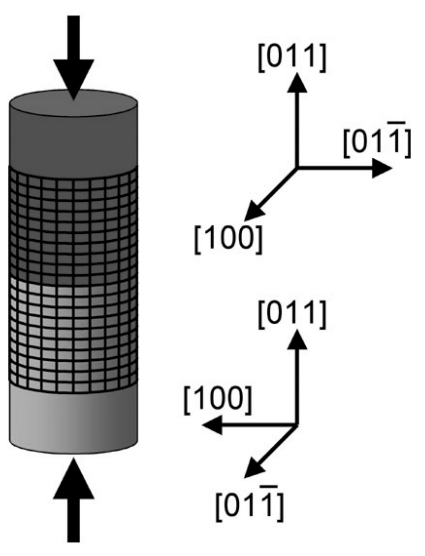

Figure 1 Bicrystal geometry with $90^{\circ}$ twist boundary and the [011] compression axis.

\section{RESULTS AND DISCUSSION}

The results are presented in terms of the macroscopic deformation behavior, which is then related to the processes and associated observations at and near the grain boundary inside the bicrystal. 
The results of the topographic shape reconstruction are presented in Fig. 2, showing the twofold symmetry develop in the bicrystal as the deformation increases from $10 \%$ to $30 \%$ strain. The top and bottom end of the sample deform according to Ta-single crystal deformation experiments [6] whereby the initially circular sample diameter evolves into an ellipse, Fig. 3.

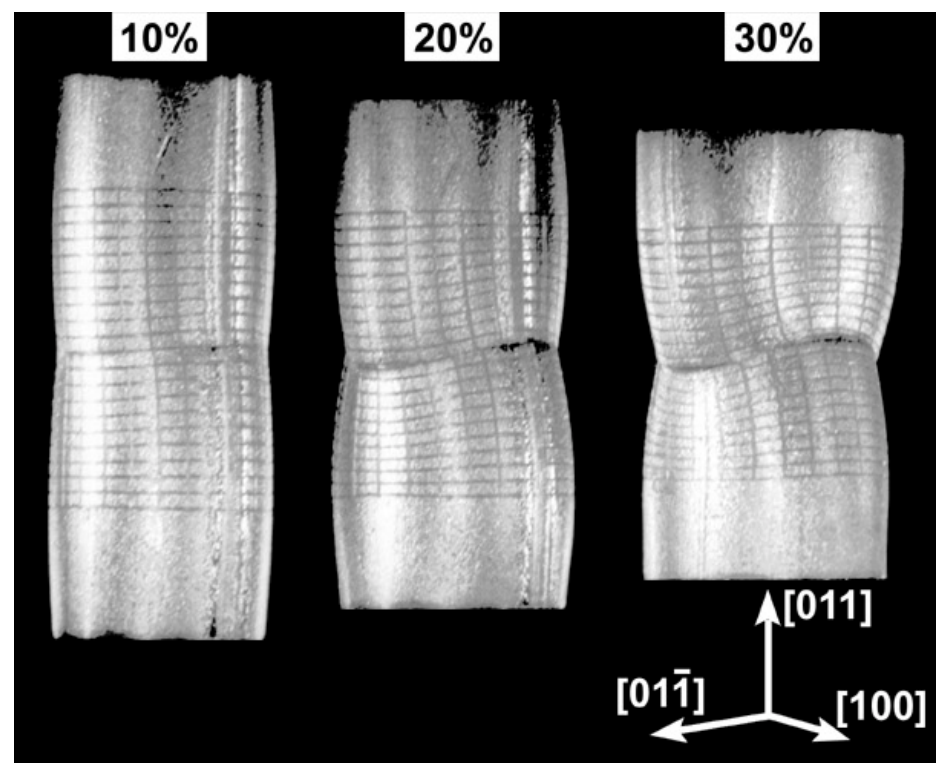

Figure 2 Plastically deformed Ta-bicrystal at 10, 20 and $30 \%$ strain showing two-fold symmetry due to the grain boundary.

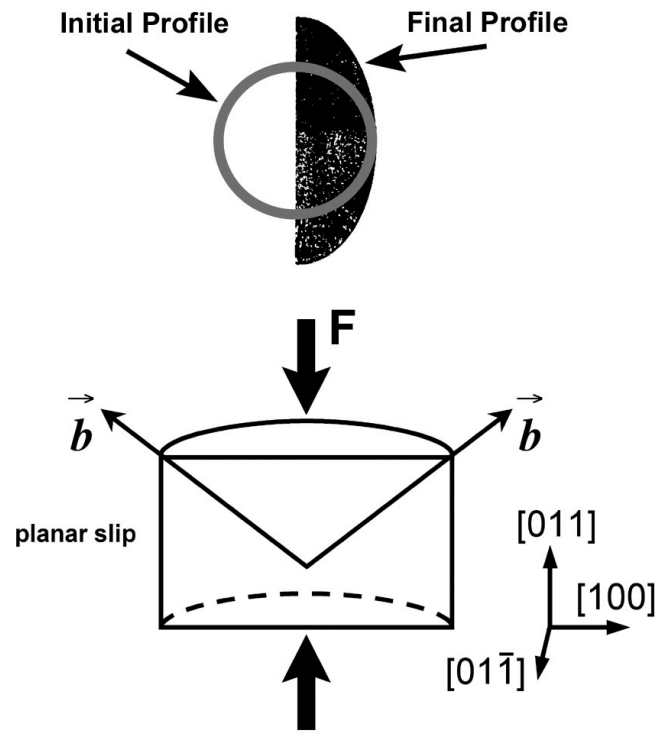

Figure 3 Deformation behavior of a Ta-single crystal. The initial and final profile reveal the planar slip occurring in the (01-1) plane.

When compressing along the [011] axis the crystal tends to respond with deformation almost entirely in the (01-1) plane and predominantly the [100] direction and by lattice rotation about the [01-1] axis. However, as seen in Fig. 2 the $90^{\circ}$ twist grain boundary clearly disturbs this deformation behavior. Both single crystals do not conform with the single crystal response to compression loading at the boundary plane and from the cross-sections presented in Fig. 4 it becomes obvious that the grain boundary is highly constrained, thus allowing only little lateral deformation.

Figure 4 The grain boundary deformation behavior clearly shows that the boundary is highly constrained and saddle shaped. High constraint results in only limited lateral deformation. The inscribed circle at left shows what grain boundary profile is predicted by crystal plasticity models.

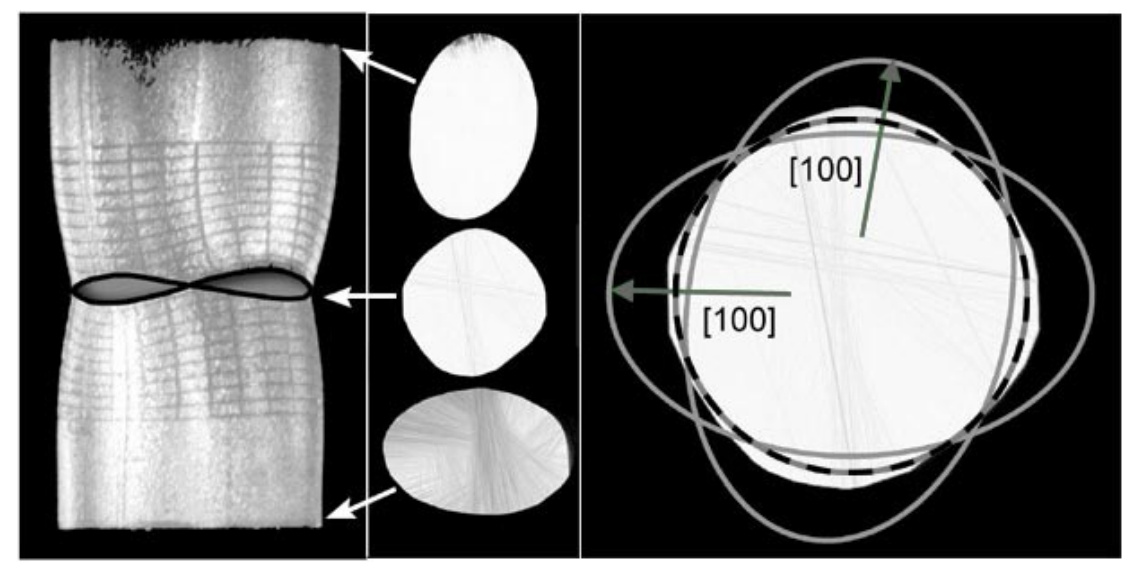


This is in contrast to crystal plasticity model calculations, that predict a perfectly circular sample cross-section at the grain boundary plane. Fig. 4 also depicts the grain boundary profile after deformation. The initially flat grain boundary evolved into a more saddle-shaped boundary adjusting to the twist-boundary constraint of the single crystals on both sides.

The highly constrained, yet deformable grain boundary can also be detected in the plots of the effective states of stress and strain over the cross-sectional area as a function of distance from the grain boundary, presented in Fig. 5a-c.
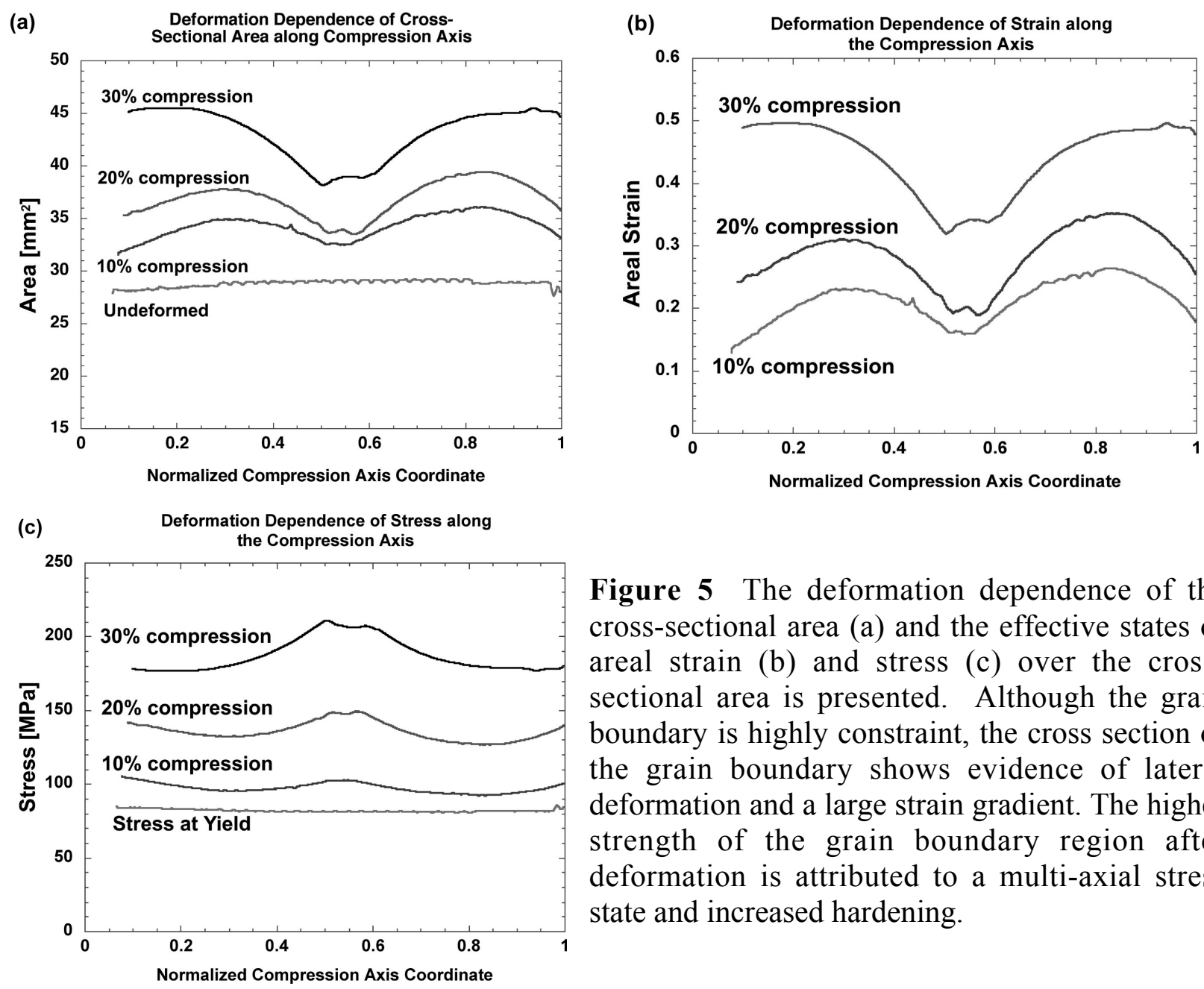

Figure 5 The deformation dependence of the cross-sectional area (a) and the effective states of areal strain (b) and stress (c) over the crosssectional area is presented. Although the grain boundary is highly constraint, the cross section of the grain boundary shows evidence of lateral deformation and a large strain gradient. The higher strength of the grain boundary region after deformation is attributed to a multi-axial stress state and increased hardening.

The deformation dependence of the cross-sectional area over the compression axis (Fig. 5a) shows how the constrained boundary allows for a small degree of lateral deformation by adjusting its absolute cross-sectional area in response to sample deformation. The area increases from initially $29 \mathrm{~mm}^{2}$ to approximately $38.5 \mathrm{~mm}^{2}$ at $30 \%$ strain. Fig. $5 \mathrm{~b}$ shows the corresponding deformation dependence of the areal strain along the compression axis and the large strain gradient caused by the grain boundary. The downturn of the curves at both end of the compression axis in both graphs is an experimental sample end-effect, which is due to the lateral friction forces acting between the sample and the flanges used for compression. The deformation dependence of the effective stress state along the compression axis shown in Fig. 5c, shows how the grain boundary region is stronger. Its constraint and the multi-axial stress state lead to increased hardening. 
The results of the EBSD scans are presented in Figs. 6, 7 and 8 where the lattice rotation maps of the bicrystal are compared to observations made on single crystals. The lattice rotation map of Ta-single crystal (Fig. 6) exhibits a particular pattern of alternating lattice rotation throughout the entire sample. This pattern, when viewed at larger magnification, reveals a network of lattice rotation bands that comprise most of the crystal lattice rotation, while the areas in between those bands do not show evidence of lattice rotation activity. It is important to note though, that these lattice rotation bands do not coincide with the traces of the $\{110\}$ or $\{112\}$ slip planes.

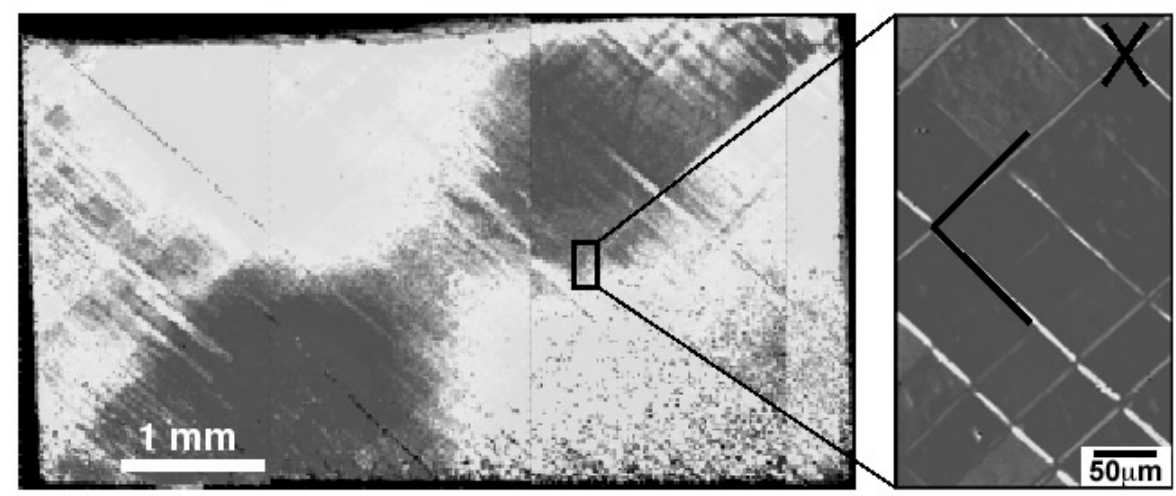

Figure 6 A Ta-single crystal deformed under compression [4] showing patterns of alternating lattice rotation crossing the sample cross-section at $\sim 45^{\circ}$. The enlargement at right reveals the individual lattice rotation bands (bright lines) [6].

Very similar lattice rotation bands and the alternating pattern can be observed to occur in the bicrystal, away from the constrained grain boundary region, Fig. 7 and 8. However, this type of activity cannot be detected anymore close to the grain boundary. Near the boundary the EBSD map shows an area that does not exhibit those band patterns.

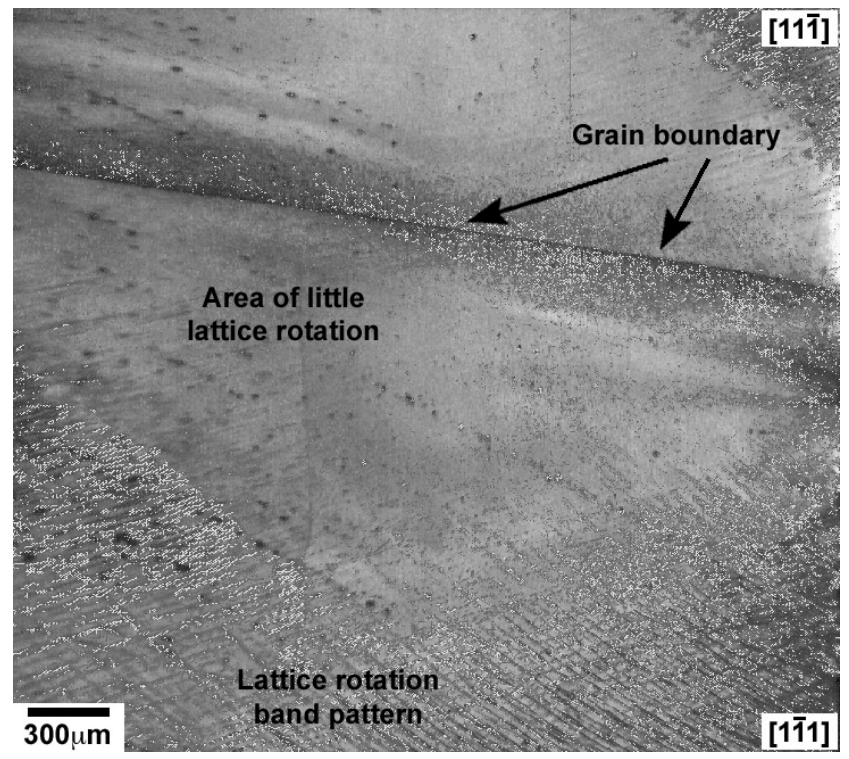

Figure 7 Lattice rotation features observed in bicrystal are similar to those in single crystal, however, the highly constraint grain boundary affects this patterns. Areas with no evidence of lattice rotation bands prevail close to the grain boundary after plastic deformation.

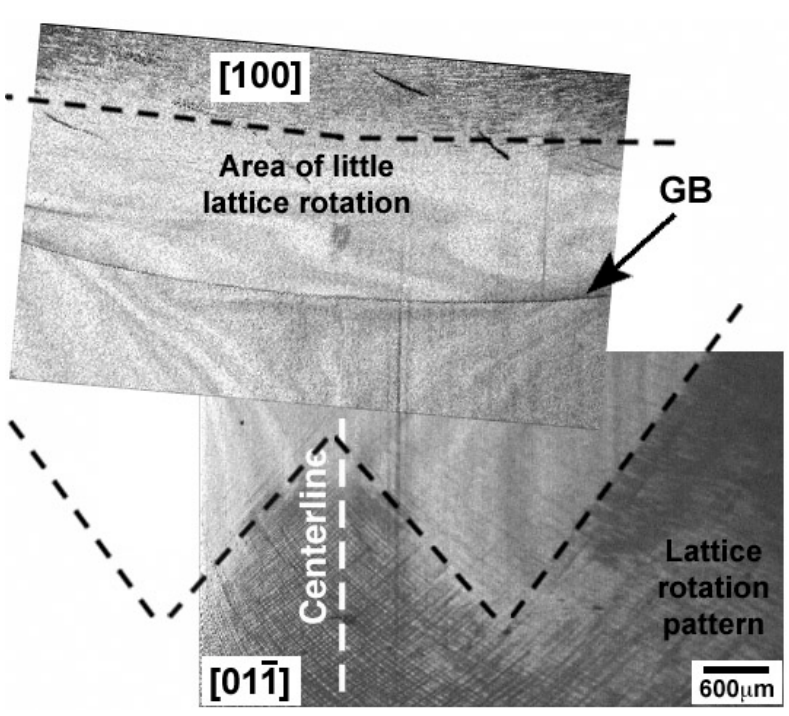

Figure 8 Evidence of non-symmetrical lattice rotation patterns can be seen on opposite sides of the grain boundary. 
It is important to note that this area is with several $100 \mathrm{~mm}$ relatively large, stretching all along the grain boundary perimeter. Moreover, this area is not symmetrical across the boundary (see Fig. 8). In the crystal oriented along [100] the lattice rotation patterns appears to run parallel to the grain boundary, while in the crystal opposite the boundary - [01-1] orientation - a similar pattern in shape of a "W" appears at approximately $+/-45^{\circ}$ to the grain boundary. However, there is rotational symmetry, caused by the $90^{\circ}$ twist boundary, which can also be seen in Fig. 7, where the bicrystal is rotated by $45^{\circ}$ and thus oriented such that both crystals are viewed along [11-1] and [1-11] respectively. The lattice rotation patterns appear to be symmetrical across the boundary in this image, thus representing the transition from the "parallel line" to the "W" pattern.

\section{CONCLUSIONS}

A highly constrained $90^{\circ}$ twist-grain boundary in a Ta-bicrystal was found to clearly disrupt the homogeneous deformation behavior of know to Ta-single crystals. The overall response of the bicrystal to plastic deformation, ranging from $10 \%$ to $30 \%$ total engineering strain did show similar features to the single crystal experiment only in the non-constrained regions of the sample, away from the grain boundary, i.e., planar slip deformation predominantly in the (0-11) plane and an elliptical cross-sectional profile. However, close to the grain boundary the cross-sectional profile did not deform accordingly and remained highly constrained exhibiting only limited lateral deformation; in contrast to crystal plasticity model calculations that predict a perfectly circular cross-section at the grain boundary plane. The grain boundary did adjust though to the deformation of the adjacent crystals by taking on a more saddle shaped profile.

A large strain gradient could be measured near the grain boundary and the boundary itself presented a stronger area of the sample. This was attributed to the constraint and the multi-axial stress state, causing thus increased hardening.

The examination using EBSD resulted in lattice rotational patterns, resembling observations made in the corresponding single crystal deformation experiments, however, the constrained grain boundary affected the distribution of such patterns. Large areas, spanning several $100 \mu \mathrm{m}$ along and cross the grain boundary, with no evidence of lattice rotation were observed on both sides of the grain boundary. Moreover, there was a clear sign of broken symmetry across the grain boundary in regard to these patterns of lattice rotation.

\section{ACKNOWLEDGEMENTS}

This work was performed under the auspices of the U.S. Department of Energy by the University of California, Lawrence Livermore National Laboratory under Contract W-7405-Eng48.

\section{REFERENCES}

1. S. V. Harren, H. E. Deve, R. J. Asaro, Acta. Met. 36, 2435 (1988).

2. $\quad$ R. Becker, Acta Met. Mat. 39, 1211 (1991).

3. A. Sutton, R. Balluffi, Interfaces in Crystalline Materials, p.737 (1995).

4. R. L. Smialek, T. E. Mitchell, Phil. Mag. 22, 1105 (1970).

5. T. A. Mason, B. L. Adams, J. of Metals 46, 43 (1994).

6. A. J. Schwartz, J. S. Stölken, W. E. King, G. H. Campbell, Mat. Sci. Eng. A317, 77 (2001). 